\title{
Sentinel 1A SAR Backscattering Signature of Maize and Cotton Crops
}

\author{
R. Kumaraperumal*, M. Shama, Balaji Kannan K.P. Ragunath and R. Jagadeeswaran \\ Department of Remote Sensing and GIS \\ Tamil Nadu Agricultural University, Coimbatore - 641003.
}

\begin{abstract}
Crop discrimination is a key issue for agricultural monitoring using remote sensing techniques. Synthetic Aperture Radar (SAR) data are advantageous for crop monitoring and classification because of their all-weather imaging capabilities. The multi-temporal Sentinel 1A SAR data was acquired from $08^{\text {th }}$ August, 2015 to $23^{\text {rd }}$ January, 2016 at 12 days interval covering the extent of Perambalur district of Tamil Nadu. Both the Vertical - Vertical (VV) and Vertical-Horizontal (VH) polarized data are compared. The ground truth data collection was performed for cotton and maize during the vegetative, flowering and harvesting stages. The temporal backscattering coefficient $\left(\sigma^{0}\right)$ for cotton and maize are extracted using the training datasets. The mean backscattering values for cotton during the entire cropping period ranges from $-10.58 \mathrm{~dB}$ to $-6.28 \mathrm{~dB}$ and -20.59 $\mathrm{dB}$ to $-14.53 \mathrm{~dB}$ for $\mathrm{VV}$ and $\mathrm{VH}$ polarized data respectively, and for maize it ranges from $-11.08 \mathrm{~dB}$

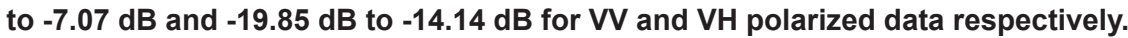

Key words: Sentinel 1A, SAR Backscattering signature, Maize, Cotton

Agricultural crops are the important food source for most of the terrestrial species. As a result, the monitoring of crops and their growth stages and discrimination between the crops are considered most important. Monitoring the crop phenology and observing their conditions within the growing season allows the farmers to modify the cultivation practice as needed. Crop discrimination is a critical first step which allows to discriminate between crop types, mapping the cropped area and estimating the yield at early stage. For these purposes, the use of remote sensing is essential. Optical remote sensing for crop monitoring has increased over the past several years and become one of the major civilian operational applications. However, several images acquired at specific times during the crop growth cycle are required to reach a suitable accuracy. This temporal constraint limits the use of optical data for operational applications because cloud cover may prevent or delay image acquisitions in many places. Space borne Synthetic Aperture Radar (SAR) imagery is able to observe the Earth's surface independently of such conditions as cloud cover and guarantees a temporal frequency of images throughout the growing period (Boerner et al., 1987).

In the case of SAR polarimetry, the sensitivity of microwave polarization to crop structure (size, shape, and orientation of leaves, stalks, and fruits), dielectric properties (related to the water content), and the physical properties of the underlying soil (roughness and moisture) varies as a function of crop type, growth stage and crop condition (Haldar et al., 2012 and lyyappan et al., 2014). As a fact, different crops types, or the same type at different growth stages,

*Corresponding author email: kumaraperumal.r@tnau.ac.in produce different polarimetric signatures, which can be identified in the acquired images. The objective of this paper is to exploit the potential of polarimetric Sentinel 1A SAR data for monitoring and extraction of backscattering signature at different phenological stages of Maize and Cotton crop in Perambalur district of Tamil Nadu.

\section{Material and Methods}

Sentinel1-A, carrying a C-band radar system with VV (Vertical-Vertical) and VH (Vertical-Horizontal) polarization obtained by interferometric wide (IW) swath mode (1) of High Resolution (HR) and processed at Level-1 ground range (GRD) is used for this study. In order to have a full coverage during the crop growing period of Maize and Cotton in Perambalur district of Tamil Nadu, the Sentinel $1 \mathrm{~A}$ data were downloaded from $8^{\text {th }}$ August 2015 to $23^{\text {rd }}$ January 2016 at 12 days interval from the Sentinel Scientific Data Hub - Copernicus website (https:// scihub.copernicus.eu/dhus/). The satellite pass is not available between $1^{\text {st }}$ September 2015 and $19^{\text {th }}$ October 2015.

Pre-processing of the satellite images were performed to suppress the unwanted distortion or to enhance the image features important for further processing. The pre-processing operations like Orbital correction, Subsetting, Border Noise Removal (Carlo, 2015), Radiometric calibration (Rosich and Meadows, 2004; Laur et al., 2004 and Lavalle and Wright, 2009), Geometric correction (Range Doppler Terrain Method), Co-registration, Layer stacking, Multi-temporal speckle filtering (Quegan et al., 2000) and Linear to $\mathrm{dB}$ conversion was done using Sentinel 1 toolbox. 
The ground survey was conducted during the month of October, November and December 2015 in the cotton and maize growing areas for extraction of backscattering signatures. The survey was planned in such a manner to collect information at different stages of the crop viz., vegetative, tasseling / boll formation and harvesting. Totally sixty-nine points were surveyed for maize (39 points) and cotton (30 points) and they were geocoded using the GPS Latitude and Longitude values using Sentinel 1 toolbox. Further, the temporal backscattering signature values were derived using the geocoded points for $\mathrm{V}-\mathrm{V}$ and $\mathrm{V}-\mathrm{H}$ polarization separately for further analysis.

\section{Results and Discussion}

The radar backscattering coefficient $(\sigma 0)$ is a measure of crop biomass, plant height, water content, underlying soil, crop phenology etc. The SAR data

Table 1. Temporal backscattering signature ( $\sigma 0$ values) for Cotton

\begin{tabular}{lcccccc}
\hline & \multicolumn{3}{c}{ VV Polarization } & \multicolumn{3}{c}{ VH Polarization } \\
\cline { 2 - 6 } Date of Satellite pass & Minimum (dB) & Maximum (dB) & Mean (dB) & Minimum (dB) & Maximum (dB) & Mean (dB) \\
\hline 08-Aug-15 (D1) & -12.62 & -7.53 & -10.58 & -20.05 & -16.33 & -20.59 \\
20-Aug-15 (D2) & -12.79 & -6.11 & -9.78 & -19.88 & -16.15 & -19.87 \\
01-Sep-15 (D3) & -12.90 & -7.20 & -10.34 & -19.38 & -16.52 & -20.35 \\
19-Oct-15 (D4) & -10.25 & -4.34 & -7.43 & -16.32 & -14.11 & -16.13 \\
31-Oct-15 (D5) & -9.56 & -2.67 & -6.28 & -14.87 & -13.05 & -14.96 \\
12-Nov-15 (D6) & -9.68 & -4.22 & -7.08 & -14.47 & -13.33 & -15.23 \\
24-Nov-15 (D7) & -9.52 & -5.01 & -7.05 & -14.99 & -13.59 & -14.89 \\
06-Dec-15 (D8) & -10.22 & -4.32 & -7.68 & -14.67 & -13.01 & -14.53 \\
18-Dec-15 (D9) & -10.26 & -4.99 & -7.57 & -15.17 & -13.59 & -15.24 \\
30-Dec-15 (D10) & -11.57 & -5.26 & -8.34 & -16.59 & -13.83 & -16.35 \\
11-Jan-16 (D11) & -11.91 & -6.61 & -8.59 & -16.52 & -14.39 & -16.27 \\
23-Jan-16 (D12) & -12.02 & -3.74 & -9.11 & -16.80 & -14.44 & -16.51 \\
\hline
\end{tabular}

collected during the cropping period were processed and analyzed using the training pixels to derive the temporal backscattering coefficient $(\sigma 0)$ for Cotton and Maize. The minimum, maximum and mean temporal backscattering signature for Vertical-Vertical (VV) and Vertical-Horizontal (VH) polarized SAR data

Table 2. Temporal backscattering signature ( $\sigma 0$ values) for Maize

\begin{tabular}{lcccccc}
\hline \multirow{2}{*}{ Date of Satellite pass } & \multicolumn{3}{c}{ VV Polarization } & \multicolumn{3}{c}{ VH Polarization } \\
\cline { 2 - 6 } & Minimum (dB) & Maximum (dB) & Mean (dB) & Minimum (dB) & Maximum (dB) & Mean (dB) \\
\hline 08-Aug-15 (D1) & -13.77 & -1.52 & -11.08 & -23.19 & -15.51 & -19.85 \\
20-Aug-15 (D2) & -12.86 & -1.20 & -10.00 & -22.87 & -16.14 & -19.37 \\
01-Sep-15 (D3) & -13.25 & -1.35 & -10.28 & -23.04 & -16.12 & -19.39 \\
19-Oct-15 (D4) & -12.09 & 1.20 & -8.48 & -18.83 & -12.15 & -16.07 \\
31-Oct-15 (D5) & -9.19 & 1.86 & -7.07 & -16.53 & -11.54 & -14.40 \\
12-Nov-15 (D6) & -10.56 & 1.33 & -7.75 & -17.26 & -11.93 & -14.89 \\
24-Nov-15 (D7) & -10.61 & 1.11 & -7.73 & -16.72 & -11.80 & -14.47 \\
06-Dec-15 (D8) & -10.48 & -0.89 & -8.33 & -16.44 & -11.01 & -14.14 \\
18-Dec-15 (D9) & -11.28 & -0.32 & -8.47 & -17.38 & -11.99 & -14.92 \\
30-Dec-15 (D10) & -12.32 & -1.02 & -9.59 & -18.39 & -13.66 & -16.17 \\
11-Jan-16 (D11) & -13.56 & -1.41 & -10.03 & -18.54 & -13.35 & -16.37 \\
23-Jan-16 (D12) & -14.30 & -1.63 & -10.46 & -19.87 & -13.38 & -16.76 \\
\hline
\end{tabular}


for cotton and maize are given in Tables 1 and 2 . The mean backscattering values for cotton crop during the entire cropping period ranges from $-10.58 \mathrm{~dB}$ to $-6.28 \mathrm{~dB}$ and from $-20.59 \mathrm{~dB}$ to $-14.53 \mathrm{~dB}$ for $\mathrm{V} V$ and
The mean backscatter value for cotton crop during the harvest ( $\sigma 0 \mathrm{D} 10)$ to post harvest stage ( $\sigma 0 \mathrm{D} 12)$ has decreased to the maximum of $1.54 \mathrm{~dB}$ in $\mathrm{VV}$ and 1.27 in $\mathrm{VH}$ when compared to the developed

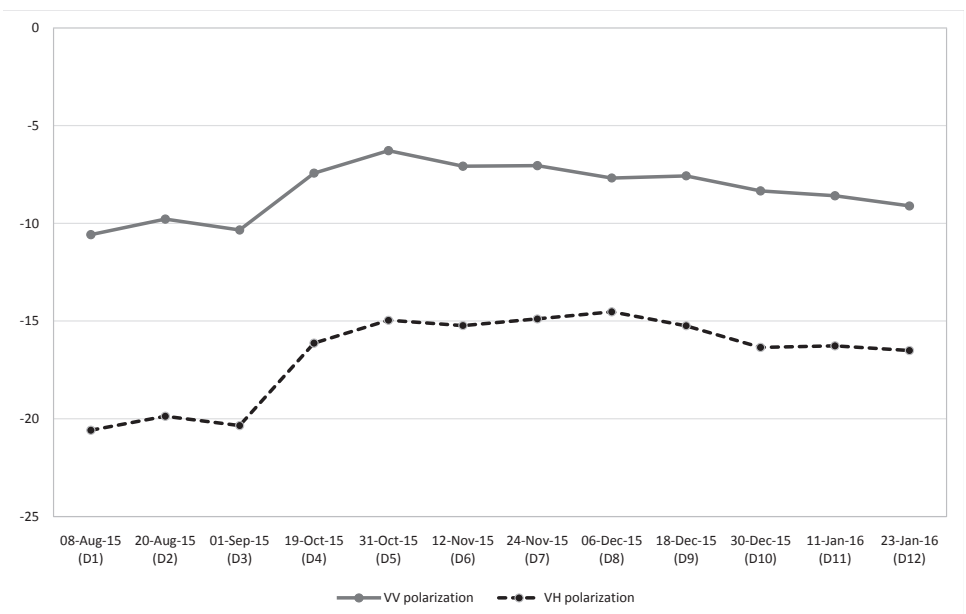

Fig 1. Mean Temporal backscattering signature of Cotton crop

$\mathrm{VH}$ polarization respectively. For maize crop it ranges from $-11.08 \mathrm{~dB}$ to $-7.07 \mathrm{~dB}$ and from $-19.85 \mathrm{~dB}$ to $-14.14 \mathrm{~dB}$ for $\mathrm{V} \mathrm{V}$ and $\mathrm{VH}$ polarized data respectively. When comparing the mean $\sigma 0$ of $\mathrm{VH}$ with $\mathrm{VV}$ polarization of cotton crop, it is found that $\mathrm{VV}$ backscattering is lesser by $9.66 \mathrm{~dB}$ to $13.76 \mathrm{~dB}$ at different stages of crop growth. Similarly, for maize crop, backscattering is lesser by $5.82 \mathrm{~dB}$ to $9.37 \mathrm{~dB}$. This shows that $\mathrm{VV}$ polarization is more sensitive in acquiring the surface variation than $\mathrm{VH}$ and this in line with work reported by Aubert et al. (2011). crop stage of $\sigma 0 \mathrm{D} 9$. Similar trend was found in the maize signature and values were decreased to the maximum of $1.99 \mathrm{~dB}$ in $\mathrm{VV}$ and $1.84 \mathrm{~dB}$ in $\mathrm{VH}$ polarization. The decrease in backscatter value may probably due to the maturity of crop, which lowers the water content of vegetation (Lillesand and Kiefer, 1994) or related to the vegetation biomass (Skriver et al., 1999) and or related to the reduced volumetric scattering due to maturity (drying and fall of lower leafs) (Panigrahy and Mishra, 2003). In both VV and $\mathrm{VH}$, the mean backscatter scatter value for cotton

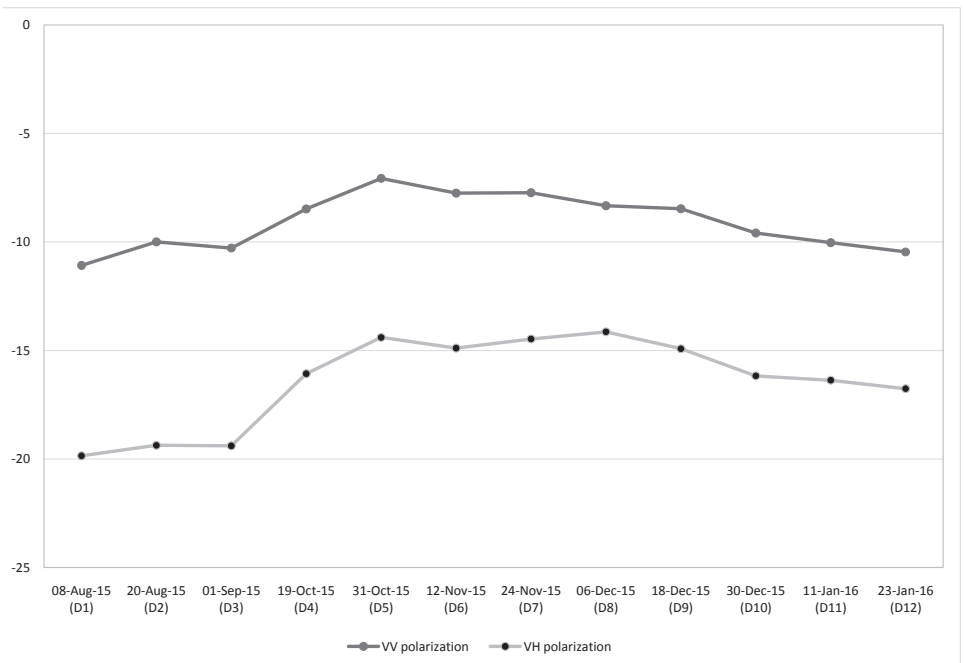

Fig 2. Mean Temporal backscattering signature of Maize crop

In both cotton and maize signature it is found that the mean backscatter value during the land preparation ( $\sigma 0 D 1)$ to initial crop growth period ( $\sigma 0 \mathrm{D} 3)$ shows lesser scattering in both $\mathrm{V}$ and $\mathrm{VH}$ when compared to the further crop development stages ( $\sigma 0 \mathrm{D} 4$ to $\sigma 0 \mathrm{D} 9$ ). This might be the due to soil moisture variation (Xavier Blaes and Pierre Defourny, 2003) or sowing which made the soil surface smoother (Karjalainen et al., 2004). crop has increased by around $4.0 \mathrm{~dB}$ during the vegetative, flowering and boll formation stages (б0D4 to O0D9) when compared to the initial establishment period ( $\sigma 0 D 3$ ) (Fig 1). Similar trend was found in maize signature and it shows an increase in mean backscatter scatter value ranges from 3 to $5 \mathrm{~dB}$ during the vegetative, flowering and cob formation stages ( $\sigma 0 D 4$ to $\sigma 0 D 9$ ) (Fig 2). The increase in mean backscattering may be caused due to the increase in 
vegetation biomass as reported by Xavier Blaes and Pierre Defourny (2003). While comparing the mean backscattering values of cotton and maize at the peak crop growth stage ( $\sigma 0 \mathrm{D} 4$ to $\sigma 0 \mathrm{D} 9)$ shows an increase in value of $1.0 \mathrm{~dB}$ to $2 \mathrm{~dB}$ was observed and it clearly indicates that the crop geometry, volumetric backscattering from crop canopy and biomass leads to this increase (Fig 1 and Fig 2). Several research works are in line with these results (Haldar et al., 2014, Shang et al., 2009 and Xavier Blaes and Pierre Defourny, 2003)

While considering the entire crop period of cotton, the minimum backscattering value of $-12.90 \mathrm{~dB}$ at $\sigma 0 \mathrm{D} 3$ and $-20.05 \mathrm{~dB}$ at $\sigma 0 \mathrm{D} 1$ is recorded during the land preparation stage for $\mathrm{VV}$ and $\mathrm{VH}$ polarization respectively. Similarly, the maximum backscattering value of -2.67 at $\sigma 0 \mathrm{D} 5$ and $-13.01 \mathrm{~dB}$ at $\sigma 0 \mathrm{D} 8$ is recorded during the vegetative to boll formation stage for $\mathrm{V}$ and $\mathrm{VH}$ polarization respectively. In case of maize, the minimum backscattering value of $-14.30 \mathrm{~dB}$ at $\sigma 0 \mathrm{D} 12$ and $-22.87 \mathrm{~dB}$ at $\sigma 0 \mathrm{D} 2$ is recorded during the land preparation stage for $\mathrm{V}$ and $\mathrm{VH}$ polarization respectively and the maximum backscattering value of 1.86 at $\sigma 0 \mathrm{D} 5$ and $-11.01 \mathrm{~dB}$ at $\sigma 0 \mathrm{D} 8$ is recorded during the vegetative to cob formation stage for $\mathrm{VV}$ and $\mathrm{VH}$ polarization respectively. From the above results it clear that the maize crop has recorded the highest backscattering value during the peak growth stage and this might be due to higher biomass content in maize when compared to cotton crop. This is line with the work done by Soria-Ruiz et al. (2001) and Macelloni et al. (2001).

\section{Conclusion}

It is evident from the present study, that the multi-temporal Sentinel 1-A SAR sensor can be well used for the discrimination of cotton and maize crops because of its high temporal resolution which captures the complete phenology of the crops during the cropping period.

\section{Acknowledgment}

The authors are grateful to European Space Agency (ESA) for providing the Sentinel 1ASAR images and technical tools (Sentinel toolbox) free of cost.

\section{References}

Aubert, M., N. Baghdadi, M. Zribi, A. Douaoui, C. Loumagne, F. Baup, M. El Hajj and S. Garrigues. 2011. Analysis of TerraSAR-X data sensitivity to bare soil moisture, roughness, composition and soil crust. Remote Sensing of Environment, 115: $1801-1810$

Boerner, W.M., B.Y. Foo and H.J. Eom. 1987. Interpretation of the polarimetric co-polarization phase term in radar images obtained with JPL airborne L-band SAR system. IEEE Transactions on Geoscience and Remote Sensing, 25 (1): 77-82.

Carlo, 2015. Masking "No-value" Pixels on GRD Products generated by the Sentinel-1 ESA IPF, Mission Performance Centre, Reference (MPC-0243), Issue (1).
Haldar, D, Anup Das, S. Manoj Yadav, Ramesh, Hooda, Shiv Mohan and Manab Chakraborty. 2014. Analysis of Temporal Polarization Phase Difference for Major Crops in India. Progress in Electromagnetic Research (PIER) B, 57: 299-309.

Haldar, D., A. Das, S. Mohan, O. Pal, R.S. Hooda and M. Chakraborty. 2012. Assessment of L-band SAR data at different polarization combinations for crop and other land use classification. Progress in Electromagnetic Research (PIER) B, 36: 303-321.

Iyyappan, M., S.S. Ramakrishnan and K. Srinivasa Raju. 2014. Study of discrimination between plantation and dense scrub based on backscattering behavior of C Band SAR data. The International Archives of the Photogrammetry, Remote Sensing and Spatial Information Sciences, XL (8): 755-760.

Karjalainen, M., H. Kaartinen, J. Hyyppa, H. Laurila and R. Kuittinen. 2004. The Use of ENVISAT Alternating Polarization SAR Images in Agricultural Monitoring in Comparison with RADARSAT-1 SAR Images. Proceedings of XXth International Society for Photogrammetry and Remote Sensing (ISPRS), July 12-23, 2004 Istanbul, Turkey. p.132-137.

Laur, H., P. Bally, P. Meadows, B. Sinchez, E. Lopinto and D. Esteban. 2004. ERS SAR Calibration: Derivation of $\sigma 0$ in ESA ERS SAR PRI Products, ESA/ESRIN, Document No. ES-TN-RS-PM-HL09, Issue 2, Revision (5f).

Lavalle, M. and T. Wright. 2009. Absolute Radiometric and Polarimetric Calibration of ALOS PALSAR Products. Document Issue (1), Revision (3).

Lillesand, T. M., and R.V. Kiefer. 1994. Remote sensing and Image Interpretation,(3- Ed.). John Willev and Sons, New York, p.750.

Macelloni, G., S. Paloscia, P. Pampaloni, F. Marliani and M. Gai. 2001. The relationship between the back scattering coefficient and the biomass of narrow and broad leaf crops. Geoscience Remote Sensing, 39: 873-884.

Panigrahy, R.K. and A.K. Mishra. 2003. An Unsupervised Classification of scattering behaviour using Hybrid Polarimetry. IET Radar, Sonar and Navigation, 7(3): 270-276.

Quegan, S., T.L. Toan, J.J. Yu, F. Ribbes and N. Floury. 2000. Multitemporal ERS SAR Analysis Applied to Forest Mapping. IEEE Transactions on Geoscience and Remote Sensing, 38 (2):741-753.

Rosich, B. and P. Meadows. 2004. Absolute calibration of ASAR Level 1 products. ESA/ESRIN, Document No. ENVI-CLVL-EOPG-TN-03-0010, Issue 1, Revision (5).

Shang, J., H. McNairn, C. Champagne and X. Jiao. 2009. Contribution of multi-frequency, multi-sensor, and multi-temporal radar data to operational annual crop mapping. IEEE Transactions on Geoscience and Remote Sensing, 3(1): III378-III381.

Skriver, H., M.T. Svendsen and A.G. Thomsen. 1999. Multitemporal C- and L-band polarimetric signatures of crops. IEEE Transactions on Geosciences and Remote Sensing, 37(5): 2413-2429.

Soria-Ruiz, J., Y. Fernandez-Ordonez and H. McNairm. 2001. Crop monitoring and crop yield using optical and microwave remote sensing. Geoscience and Remote Sensing, 38(5): 405-419.

Xavier Blaes and Pierre Defourny. 2003. Retrieving Crop Parameters Based on Tandem ERS 1/2 Interferometric Coherence Images. Remote Sensing of Environment, 88: $374-385$. 